\section{Anaphylactic Shock due to Non-Ruptured Hydatid Cyst of Liver}

Sir,

A29-yearfemale patient was brought to the Emergency Department around 6.00 AM. Her Glasgow coma score (GCS) was 9, systolic blood pressure (SBP) $60 \mathrm{mmHg}$, diastolic blood pressure (DBP) $0 \mathrm{mmHg}$, pulse $150 / \mathrm{min}$, and $\mathrm{O}_{2}$ saturation $\left(\mathrm{SpO}_{2}\right)$ with fingertip pulse-oximeter was $96 \%$. Blood sugar measured was $150 \mathrm{mg} / \mathrm{dL}$. The patient was considered in anaphylactic shock. Thus, $2000 \mathrm{cc}$ of $0.9 \% \mathrm{NaCL}$ was given as rapid infusion. Adrenaline was administered $0.3 \mathrm{mg}$ subcutaneously and 70 $\mathrm{mg}$ prednisolone; and $50 \mathrm{mg}$ ranitidine and $45 \mathrm{mg}$ phenylephrine IV were given intravenously. Brain computed tomography was normal. Hydatid cyst was observed in abdominal ultrasound. The patient responded to medical treatment and SBP increased to $110 \mathrm{mmHg}$, DBP to $67 \mathrm{mmHg}$, and pulse rate declined to $105 / \mathrm{min}$. She regained consciousness after approximately 3 hours and GCS improved to 15 . We consulted general surgery with preliminary diagnosis of ruptured hydatid cyst. After computed tomography scan of abdomen, ruptured hydatid cyst was excluded. The cyst was located in the right lobe of liver. Echinococcosis specific IgE was $43.8 \mathrm{U} / \mathrm{ml}$ (very strong positive; normal range: $0-6.0 \mathrm{U} / \mathrm{ml}$ ). The patient was admitted to general surgery clinic for 2 days with diagnosis of non-ruptured hydatid cyst. She was then discharged and outpatient treatment was arranged. She was given albendazole $15 \mathrm{mg} / \mathrm{Kg} / \mathrm{day}$, divided into 2 doses per day for 3 weeks. Her condition improved with medical treatment and was advised to come for follow-ups. Hydatid cyst wall is made up of two layers, endocyst and exocyst. The protective outer layer comprises of mucopolysaccharide structure and is called exocyst, and the fertile inner layer, where the vesicles and scoleces are born is called endocyst. Inside the cyst is a clear, sterile but antigenic liquid called rock water. Anaphylactic shock caused by echinococcosis was found to be an IgE-related allergic reaction. ${ }^{1}$ Most of the patients had IgE, which is developed against echinococcus granulosus antigens and serum IgE levels are associated with the severity of the disease. ${ }^{2}$

While $16.7-25 \%$ of patients with hydatid cyst rupture developed minor allergic reactions such as hives, 1-12.5\% patients showed more severe allergic reactions such as peripheral edema, syncope and anaphylaxis. ${ }^{3}$ In our case, there was no evidence of rupture of the hydatid cyst, but the patient devel- oped severe anaphylactic shock, which was very unusual. In our case, the cyst liquid, which is antigenic, somehow leaked without overt ruptue of the cyst, leading to anaphylaxis. In the laboratory findings of our patient, high levels of hydatid-specific IgE antibodies support this idea.

In summary, non-ruptured hydatid cyst should be kept in mind incases of anaphylaxis and anaphylactic shock.

\section{CONFLICT OF INTEREST:}

The authors declared no conflict of interest.

\section{AUTHORS' CONTRIBUTION:}

AA, BSA, KS: Substantial contributions to the conception or design of the work; or the acquisition, analysis, or interpretation of data for the work; drafting the work or revising it critically for important intellectual content; and final approval of the version.

\section{REFERENCES}

1. Sanei B, Hashemi SM, Mahmoudieh M. Anaphylactic shock caused by nonruptured hydatid cyst of the liver. J Gastrointest Surg 2008;12(12):2243-5. doi: 10.1007/ s11605-008-0468-0.

2. Ortona E, Vaccari S, Margutti P, Delunardo F, Rigano R, Profumo $E$, et al. Immunological characterisation of echinococcus granulosus cyclophilin, an allergen reactive with IgE and IgG4 from patients with cystic echinococcosis. Clin Exp Immunol 2002; 128(1):124-30. doi: 10.1046/j.1365-2249.2002.01807.x

3. Yilmaz M, Akbulut A, Kahraman A, Yilmaz S. Liver hydatid cyst rupture into the peritoneal cavity after abdominal trauma: Case report and literature review. Int Surg 2012; 97(3):239-44. doi:10.9738/CC116.1.

Akkan Avci', Begum Seyda Avci' and Kemal Sener

${ }^{1}$ Department of Emergency Medicine, Health Science University, Adana City Research and Training Hospital, Adana, Turkey

${ }^{2}$ Department of Internal Medicine, Health Science University, Adana City Research and Training Hospital, Adana, Turkey

Correspondence to: Dr. Akkan Avci, Department of Emergency Medicine, Health Science University, Adana City Research and Training Hospital, Adana, Turkey E-mail: drakkanavci@gmail.com

Received: February 19, 2020; Revised: March 15, 2020; Accepted: March 26, 2020

DOI: https://doi.org/10.29271/jcpsp.2021.02.247 